\title{
ESTUDO DA VIABILIDADE ECONÔMICA DA IMPLANTAÇÃO DE INCINERADORES DE “RSU” NA REGIÃO DE BAURU
}

\author{
Adailton Pereira de Brito ${ }^{1}$
}

Celso Luiz da Silva ${ }^{2}$

RESUMO: A principal preocupação relacionada à produção de resíduos tem sido o manejo e a gestão integrada, procedimentos que passaram a fazer parte das políticas de gestão com o objetivo de evitar problemas irreversíveis ao meio ambiente e aos seres humanos. Neste trabalho estuda-se a possibilidade da incineração dos Resíduos Sólidos Urbanos (RSU) como solução para o problema relacionado com a destinação dos resíduos gerados na Região de Bauru. Estimar os custos de capital e a viabilidade econômica para o projeto de incineradores de larga escala é uma tarefa prioritária para auxiliar o processo de tomada de decisão. Este trabalho revê a situação dos resíduos sólidos na região de Bauru e realiza revisão dos processos empregados e existentes no tratamento dos RSU com o objetivo de analisar a viabilidade da implantação de uma usina de incineração com geração de energia elétrica para o tratamento dos resíduos sólidos coletados na Região de Bauru. O estudo apresenta um retorno interessante ao passo que as simulações apresentam indicadores favoráveis a sua implantação.

Palavras-chave: Resíduos Sólidos Urbanos, Tratamento Térmico, Viabilidade Econômica.

Licenciado em Física, UNESP, mestrando em Engenharia Mecânica pela UNESP. E-mail adailton@fc.unesp.br

Professor Titular da Universidade Estadual Paulista - UNESP - FEB - Departamento de Engenharia Mecânica. E-mail celsos@feb.unesp.br, 


\section{INTRODUÇÃO}

Historicamente, o desenvolvimento e o avanço das sociedades têm estado intimamente ligados a maior produção de resíduos. O aumento na produção, e a facilidade em produzir aliada a melhoria no poder aquisitivo da população geram, cada vez mais, o consumo, conseqüentemente cada vez mais são exigidos recursos naturais para satisfazer as tais necessidades.

Os primeiros seres humanos produziam resíduos em pequenas quantidades, o que significava naturalmente que o meio era capaz de absorver esses resíduos. Além disso, os resíduos descartados não traziam nocividade ao meio ambiente por que estes eram resíduos na maioria sem toxidade e eram absorvidos pelo meio com o passar do tempo (TCHOBANOGLOUS, 1996). Não foi senão em tempos relativamente recentes que a sociedade compreendeu a partir das observações e experimentação que não é possível manter as relações entre a produção e consumo nos patamares atuais, senão resolver o problema da gestão dos resíduos gerados.

A principal preocupação relacionada à produção de resíduos tem sido o manejo e a gestão integrada, procedimentos que passaram a fazer parte das políticas de gestão, com o objetivo de evitar problemas irreversíveis ao meio ambiente e aos seres humanos.

Uma das soluções encontrada tem sido dispor esses resíduos em aterros controlados, o que freqüentemente está longe de acontecer na maioria dos municípios brasileiros. A comparação entre os dados brasileiros relativos a região sudeste resulta na constatação de um aumento de cerca de 2,6\% na destinação final ambientalmente adequada em aterros sanitários, porém $27,8 \%$ dos resíduos coletados na região, correspondentes a cerca de 26 mil toneladas diárias, ainda são destinados para lixões e aterros controlados que, do ponto de vista ambiental, pouco se diferenciam dos próprios lixões, pois não possuem o conjunto de sistemas necessários para proteção do meio ambiente e da saúde pública (ABRELPE 2011).

Por outro lado, se a implantação desses aterros tem sido uma solução, está não garante a solução para os problemas ambientais, uma vez que, quando implantados de forma inadequada causam poluição do solo, do ar e dos recursos hídricos. 
Por sua vez, a geração de energia por fontes renováveis com baixo impacto ambiental, e a criação de mecanismos para um melhor aproveitamento das áreas de destino final dos resíduos sólidos urbanos (RSU), tem sido incentivada pelos órgãos governamentais. A pesquisa neste campo tem acompanhado tal estímulo, resultando em uma série de artigos e trabalhos voltados ao assunto.

Neste contexto a opção pela incineração desses resíduos em instalações adequadas, que dispõem de sistemas eficientes de tratamento de efluentes vem sendo uma das soluções adotadas por muitos países, a exemplo dos países da comunidade européia.

A incineração é uma das alternativas para tratamento de resíduos sólidos urbanos, e que segundo Tchobanoglous (1996), pode ser definida como o processamento térmico no qual os resíduos sólidos são oxidados com quantidades de oxigênio em excesso. Hauser (2007) afirma que a incineração é um dos métodos mais eficazes no reaproveitamento dos resíduos, tanto na redução de sua potencialidade nociva ao meio ambiente, como na possibilidade de utilização para a geração de energia elétrica.

A combustão do lixo é caracterizada como o método mais eficiente para eliminar as emissões de metano caso os RSU fossem despejados em aterros, além de substituir a produção de energia a partir de combustíveis fósseis, Poletto (2008).

No Brasil existe certa desconfiança em relação ao uso do processo de incineração do lixo, isto se deve a utilização, no passado, de equipamentos obsoletos sem manutenção adequada.

A incineração, segundo Kreith (1994), fornece muitas vantagens, podendo-se citar: redução do volume e peso dos resíduos, redução imediata de resíduos, não exigindo longa permanência em aterro sanitário. Os resíduos podem ser incinerados em locais próximos ou estratégicos e as emissões gasosas podem ser efetivamente controladas não implicando em risco ambiental a atmosfera. Os produtos gerados na queima, ou seja, as cinzas são inertes, as tecnologias existentes permitem completa destruição de materiais perigosos e pode-se recuperar energia no processo.

O processo de incineração também apresenta algumas desvantagens que incluem: o elevado custo de investimento, a necessidade de mão de obra especializada e nem todos os materiais encontrados nos RSU podem ser incinerados. 


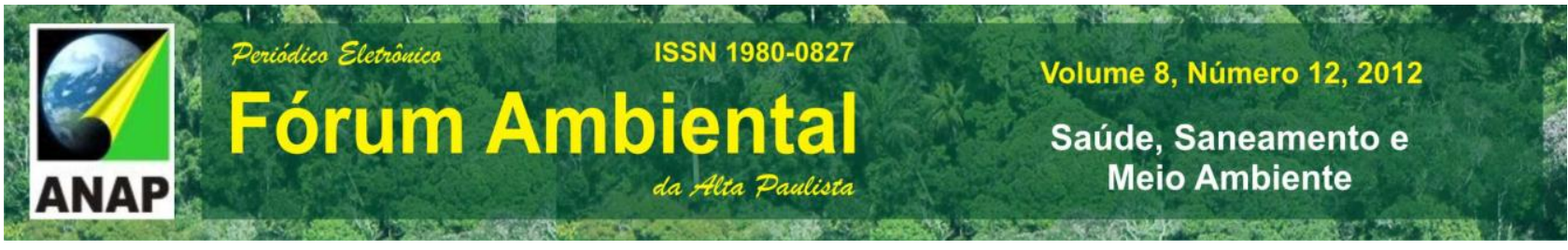

Atualmente são empregadas diversas tecnologias para a incineração dos resíduos. De acordo com Silva (1998), uma instalação moderna de incineração de RSU é constituída por: fossa de deposição de resíduos, balde de garras para alimentação da câmara de combustão, alimentador da câmara de combustão por grelhas, câmara de combustão (onde os resíduos são queimados), câmara de pós-combustão, caldeira de recuperação de energia (local onde passam os gases resultantes da queima com a finalidade de produzir vapor que pode ser utilizado diretamente em indústrias, para aquecimento ou para geração de energia elétrica), tratamento de Gases (separador de particulados, filtro de mangas, lavador de gases, filtro eletrostático), sistema de exaustão de dispersão de gases (chaminé) tratamento de efluentes líquidos gerados no processo de lavagem de gases, coleta e pré-tratamento dos efluentes sólidos (cinzas e escórias geradas nas câmaras de combustão), corpo receptor para material sólido (aterro sanitário), instalações de controle, automação e auxiliares.

A recuperação de energia durante o tratamento térmico do lixo pode ter como objetivo: geração de eletricidade e/ou vapor, resfriamento de água em ciclos de refrigeração por absorção e cogeração de energia.

Diferentes tecnologias de incineração foram desenvolvidas para tratar os vários tipos e as várias formas de resíduos. Em geral as unidades servem para incineração de resíduos sólidos, líquidos e lamas, Poletto (2008). A classificação dos sistemas utilizados para incineração é feita segundo o formato da câmara e processo de combustão realizado, dentre as diferentes tecnologias empregadas para combustão de resíduos sólidos urbanos, destacam-se: sistemas com dupla-câmara fixa, cilindro rotativos, leito fluidizado e sistemas com plasma.

A quantidade de resíduos a ser incinerado, o poder calorífico do material combustível e demais parâmetros de combustão, determinam o tipo de tecnologia a ser adotada, Saffer (2011).

A tecnologia da incineração consolida-se no mundo como uma forma permanente no processo de gestão dos resíduos sólidos, sendo que o aproveitamento energético é obtido ao mesmo tempo em que se atende a demanda quanto a resolução dos problemas referentes ao destino RSU. 
Dessa forma, propõe-se o estudo de viabilidade econômica da implantação de incineradores de RSU com aproveitamento energético em um provável consórcio de municípios na região de Bauru. $\mathrm{Na}$ avaliação será realizado estudo técnico econômico a partir dos indicadores econômicos, Valor Presente Líquido (VPL) e Taxa Interna de Retorno (TIR).

\section{METODOLOGIA}

A metodologia proposta prevê a análise econômica de formação de um possível consórcio entre as cidades da região administrativa de Bauru. Considerou-se a distribuição das seções regionais da CETESB, acrescidas de mais três municípios que estão localizados dentro de uma área de abrangência (São Manuel, Areiópolis e Botucatu).

Realizou-se levantamento bibliográfico dos dados referentes às estimativas da capacidade de geração de energia a partir da queima do RSU da região de Bauru para obter-se resultados quanto à rentabilidade financeira.

Os dados referentes aos investimentos foram levantados de diferentes fontes, assim consideraram-se os valores médios apresentados em outros trabalhos referentes ao mesmo tema.

$\mathrm{Na}$ análise da viabilidade financeira utilizaram-se os métodos VPL e TIR. O método VPL, também chamado de método do Valor Anual Líquido, tem como finalidade determinar um valor no instante inicial, a partir de um fluxo de caixa formado por uma série de receitas e dispêndios, Hirschfeld (2009).

O VPL de um fluxo de caixa é, portanto, a somatória algébrica dos valores presentes envolvidos neste fluxo de caixa, e podem ser representados pela equação 1 . Esse método é um dos mais utilizados na avaliação de investimentos, por obter o valor da produção em termos atuais, considerando uma taxa de juros, e por ser isento de falhas técnicas.

$V P L=\sum_{0}^{n} F_{n}(1+i)^{-n}(\mathbf{1})$ 
onde:

$\mathrm{VPL}=$ valor presente líquido de um fluxo de caixa.

$\mathrm{n}$ = número de períodos envolvidos em cada elemento da série de receitas e dispêndio do fluxo de caixa.

$F_{n}=$ cada um dos diversos valores envolvidos no fluxo de caixa e que ocorrem em $\mathrm{n}$.

$\mathrm{i}$ = taxa de juros comparativos ou taxa mínima de atratividade, também chamada taxa de equivalência, taxa de expectativa ou ainda, taxa de desconto.

A Taxa Interna de Retorno (TIR), é a taxa de juro ganho sobre o investimento nãorecuperado de tal forma que o esquema de pagamento reduz a zero o investimento nãorecuperado no final da vida do investimento (Newnam, Donald G., 2000)

Para Hirschfeld a TRI pode ser entendida como a taxa que faz com que o valor atualizado dos benefícios sejam iguais aos valores atualizados dos custos. Sendo um método que depende exclusivamente do fluxo de caixa de sistemas de produção, constitui uma medida relativa que corresponde ao aumento da taxa i no valor do investimento ao longo tempo, tendo em vista os recursos demandados para produzir o fluxo de receitas.

O cálculo da TIR é semelhante ao do valor presente líquido, sendo que no lugar de fixar uma taxa de desconto, esta iguala o VPL à zero para estimativa da taxa de retorno do investimento, conforme a equação 2, Hirschfeld (2009).

$$
T I R=\sum_{0}^{n} F_{n}(1+i)^{-n}=0(2)
$$

onde:

TIR= Taxa Interna de Retorno.

$\mathrm{n}$ = número de períodos envolvidos em cada elemento da série de receitas e dispêndio do fluxo de caixa.

$F_{n}=$ cada um dos diversos valores envolvidos no fluxo de caixa e que ocorrem em $\mathrm{n}$.

$\mathrm{i}$ = taxa de juros comparativos ou taxa mínima de atratividade, também chamada taxa de equivalência, taxa de expectativa ou ainda, taxa de desconto.

\subsection{Cenário Econômico}


O investimento inicial necessário do projeto inclui planejamento, construção e implantação de uma usina com capacidade de processamento entre 350 e 640 t/d (massa essa que viabiliza a recuperação energética), assim analisou-se uma planta moderna considerando sistema de co-geração e tratamento de gases, a tabela 1 apresenta alguns parâmetros importantes.

Tabela 1 - Valores referentes ao investimento.

\begin{tabular}{|l|r|}
\hline \multicolumn{1}{|c|}{ Item } & Cenário do investimento \\
\hline Investimento inicial (R\$) & $232.400 .000,00$ \\
\hline Capacidade mínima (t/d) & 350 \\
\hline Capacidade máxima (t/d) & 640 \\
\hline Eficiência líquida da planta (\%) & 26 \\
\hline Potência total (MW) & 15 \\
\hline Disponibilidade (horas/ano) & 8000 \\
\hline
\end{tabular}

Fonte: SAFFER (2011)

No estudo assume-se que o capital para o investimento seja tomado junto ao Banco Nacional do Desenvolvimento Econômico e Social (BNDES). Especificamente para a implantação de projetos de aterros sanitários, e que contemplem uma solução de tratamento dos resíduos (compostagem, "mass burning", aproveitamento energético, plantas de blendagem de resíduos, transformação de resíduos em matéria-prima, dentre outros) a participação máxima poderá chegar a 100\% dos itens financiáveis (BNDES, 2012).

Assim para o estudo utilizou-se tempo de carência de 24 meses para o pagamento dos juros principais, capitalização anual, sistemas de amortização constante (SAC) com prestações anuais e uma taxa de juros total de $9,71 \%$ ano.

Considerou-se que os custos referentes à aquisição do terreno serão de responsabilidade da administração pública, isto é, o terreno será doado pela(s) prefeitura(s) para a implantação do projeto. 
No estudo realizaram-se estimativas de todos os gastos envolvidos com o investimento. Os custos com operação da planta são estimados utilizando valores de estudos similares e incluem, tributos, encargos, gastos operacionais e manutenção estes totalizam gastos da ordem de $\mathrm{R} \$ 1.729 .026,00$ mensais.

Nas previsões supõe-se que sejam incineradas $550.400 \mathrm{~kg} /$ dia de lixo e um regime operacional de 8000 horas ao ano, segundo Maranho (2008) um sistema operando na região de Bauru com estas especificações tem capacidade de produção de $355 \mathrm{MWh} /$ dia de energia elétrica.

Optou-se por trabalhar com o valor médio da energia praticado no mercado. No cálculo de receitas adotou-se o valor médio de $\mathrm{R} \$ 170,00$ para cada MWh. Conseqüentemente para a analise de sensibilidade é estudado a variação do preço do MWh. Considera-se para a avaliação das projeções dos cenários propostos, a rentabilidade observando o valor original do MWh e variação de $+/-20 \%$ no valor Médio.

Para a destruição térmica dos RSU utilizou-se o valor de 120 reais por tonelada processada a serem cobrados pelo tratamento térmico, totalizando uma receita da ordem de $R \$ 21.993 .984 .00$ anuais.

Realizou-se avaliação do projeto como atividade do mecanismo de desenvolvimento limpo (MDL), sendo estimada a redução de emissões de gases do efeito estufa decorrentes das atividades de mitigação de gases do efeito estufa segundo metodologia empregada por Hauser (2007), na qual a partir do fator de emissão da linha de base e do fator das emissões diretas é possível calcular o fator de mitigação (FM), que quantifica a redução de $\mathrm{CO}_{2 \mathrm{e}}$ por cada tonelada de RSU.

\section{RESULTADOS}

A partir dos dados já citados na metodologia foi possível calcular total de emissões de gases de efeito estufa $\left(\mathrm{CO}_{2 \mathrm{e}}\right)$ evitadas anualmente com a incineração de 550 ton/dia de RSU, será de aproximadamente 111.674 toneladas de $\mathrm{CO}_{2}$, o que gerará uma receita anual $\mathrm{R} \$ 3.377 .028,00$ decorrente da venda dos créditos de carbono. 
Assumiu-se uma taxa real de juros de $9,71 \%$ ao ano para o financiamento do BNDES, portanto como o capital necessário para o projeto é de $R \$ 232.400 .000,00$, totalizaria juros montante de $\mathrm{R} \$ 295.775 .480,00$.

Com base nas receitas mensais do projeto, foram calculados os valores referentes aos ganhos do projeto anualmente, considerando o cenário proposto. A tabela 2 resume as estimativas dos ganhos operacionais a partir do cenário proposto de receita.

Tabela 2. Estimativas de lucro operacional anual.

\begin{tabular}{l|llll}
\hline Caso & Valor $(R \$ / M W h)$ & Destruição (t/RSU) & Credito de carbono & Receita $(R \$)$ \\
\hline 1 & Original & Original & $3.377 .028,00$ & $45.490 .206,00$ \\
2 & $+20 \%$ & Original & $3.377 .028,00$ & $46.137 .016,86$ \\
3 & $-20 \%$ & Original & $3.377 .028,00$ & 41.466 .367 .20 \\
\hline
\end{tabular}

Com o objetivo de apurar o resultado financeiro obtido no projeto da implantação do empreendimento, foi feita simulações e avaliação, foram utilizados os custos anuais praticados, constituídos de: manutenção e operação. A análise realizada, portanto, restringiram-se à avaliação dos fatores de Fluxo de Caixa.

Todas as previsões foram feitas em termos reais, ou seja, em moeda de poder aquisitivo constante. A tabela 3 mostra os resultados da Taxa Interna de Retorno (TIR) e do Valor Presente Líquido (VPL), obtidos com a avaliação dos fluxos de caixa.

Tabela 3. Resultados da avaliação

\begin{tabular}{||l|l|l||}
\hline Indicadores & $\mathrm{VPL}(\mathrm{R} \$)$ & $\mathrm{TIR}$ \\
\hline Caso 1 & $\mathrm{R} \$ 21.583 .856,88$ & $7 \%$ \\
\hline Caso 2 & $\mathrm{R} \$ 29.384 .247,06$ & $7 \%$ \\
\hline Caso 3 & $-\mathrm{R} \$ 26.942 .713,40$ & $5 \%$ \\
\hline
\end{tabular}




\section{CONSIDERAÇÕES FINAIS}

As simulações financeiras a partir dos modelos apresentados demonstraram retornos aceitáveis do investimento em dois dos casos estudados, isto é que a taxa mínima de atratividade (TMA) seja maior que 6\% ao ano, considerando investimento público, e com um valor presente líquido do empreendimento necessariamente positivo.

Os dados caracterizam que a rentabilidade do projeto depende dos preços da energia elétrica praticados pelo mercado. Este estudo desenvolveu-se considerando a seguinte forma, para cada função elegeu-se uma das variáveis independente e as outras como constante.

A análise dos possíveis cenários do projeto caracteriza um VPL negativo para o cenário 3 , porém a TIR fornece um retorno $5 \%$, é por este fato que um financiamento representa uma opção de risco, o que não descaracteriza o interesse do ponto de vista de um investimento público.

O retorno melhor é possível quando são simulados os cenário 1 e 2 , a rentabilidade do projeto depende fortemente das receitas provenientes da venda de energia, dessa forma em termos de risco, a comparação é interessante ao passo que devem ser considerados outros ganhos com o projeto.

As variações que foram estudadas neste esboço qualitativo podem influenciar na viabilidade econômica do projeto, entretanto, um projeto não pode ser reduzido somente aos seus impactos financeiros, pois associados à criação e implantação do projeto existem diversas ganhos ambientais e sociais.

\section{REFERÊNCIAS}

ABNT. NBR 6022: informação e documentação: artigo em publicação periódica científica impressa: apresentação. Rio de Janeiro, 2003. 5 p.

ABNT. NBR6023: informação e documentação: elaboração: referências. Rio de Janeiro, 2002. 24 p. 


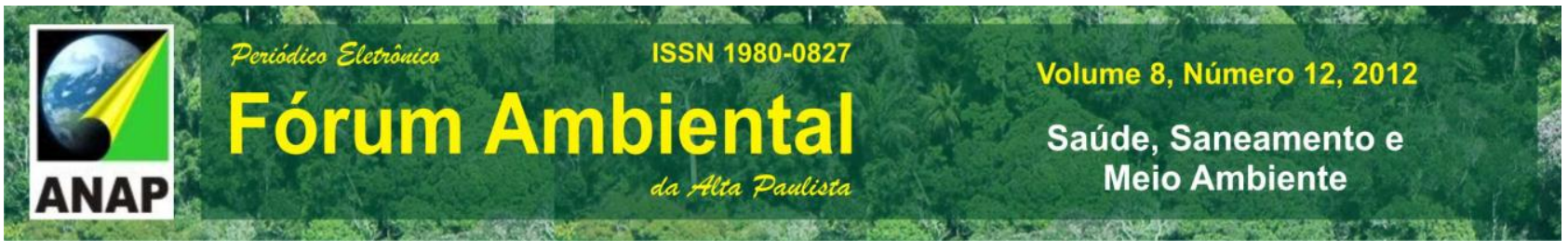

ABNT. NBR6024: Informação e documentação: numeração progressiva das seções de um documento. Rio de Janeiro, 2003. 3 p.

ABNT. NBR6028: resumos. Rio de Janeiro, 2003. 2 p.

ABNT. NBR10520: informação e documentação: citação em documentos. Rio de Janeiro, 2002. 7 p.

ABRELPE - Associação Brasileira de Limpeza Pública e Resíduos Especiais - Panorama dos resíduos sólidos no Brasil, 2011.

BNDES. BANCO NACIONAL DE DESENVOLVIMENTO ECONÔMICO E SOCIAL. Saneamento ambiental e recursos hídricos. Disponível em: http://www.bndes.gov.br/SiteBNDES/bndes/bndes pt/Areas de Atuacao/Meio Ambiente/ $>$ acessado em 02 de jun. 2012.

CETESB, COMPANHIA DE TECNOLOGIA E SANEAMENTO AMBIENTAL. Inventário Estadual de Resíduos Sólidos Domiciliares: Relatório de 2010. CETESB, São Paulo, 2010.

ENGEBIO Engenharia LTDA. Estudo da arte e de viabilidade técnica, econômica e ambiental da implantação de uma unidade de tratamento térmico de resíduos sólidos urbanos com geração de energia elétrica em uma região conjunto de municípios no estado de Minas Gerais. Relatório 1: Estado da Arte do Tratamento Térmico de Resíduos Sólidos Urbanos com Geração de Energia Elétrica, Porto Alegre, 2009, 276 p.

HAUSER, D. P.; LEMME, C. F.; Modelo de Financiamento para Projetos de Incineração de Resíduo Sólido Municipal no Ấmbito do Mecanismo de Desenvolvimento Limpo; Revista de Gestão Social e Ambiental; 2007.

KREITH, F., "Handbook of Solid Waste Management", McGraw-Hill, 1994.

MARANHO, A. S., Potencial de Geração de Energia Elétrica a Partir de Resíduos Sólidos Urbanos para Bauru e Região, Dissertação de Mestrado, UNESP-FEB, Bauru, 2008.

NEWNAN, DOLNALD G., Fundamentos de Engenharia Econômica. Rio de Janeiro; LTC, 2000. POLETTO, J. A. F. - Viabilidade Energética e Econômica da Incineração de RSU Considerando a Segregação para Reciclagem. Dissertação de Mestrado, UNESP, Bauru, 2008.

SAFFER M., DUARTE G. A. A., Estudo do Estado da Arte e Análise de Viabilidade Técnica, Econômica e Ambiental da Implantação de uma Usina de Tratamento Térmico de Resíduos Sólidos Urbanos com Geração de Energia Elétrica no Estado de Minas Gerais, 26응 Congresso Brasileiro de Engenharia Sanitária e Ambiental.

SANTOS, D. S.; Viabilidade do Aproveitamento do Lixo Urbano da Cidade de Maceió como Alternativa Energética; Dissertação de Mestrado; UFA; 2009.

SÃO PAULO. RESOLUÇÃO SMA no 79 de 04 de novembro de 2009. Estabelece diretrizes e condições para o tratamento térmico de resíduos sólidos em usinas de recuperação de energia- URE, republicado DOE de 07 de novembro de 2009. Secretária de Estado do Meio Ambiente - secção I pág. 63-65. 
SILVA, C. L.; Tratamento Térmico de Resíduos Sólidos, Apostila de Curso de Pós - Graduação - FEB/UNESP, Bauru, 1998.

TCHOBANOGLOUS, G., THEISEN, H, S., Integrated Solid Waste Management: Engineering Principles and Management Issues, McGraw-Hill, Inc. International Ed.,1996.

VILHENA A., Lixo Municipal: Manual de Gerenciamento Integrado -3ed. São Paulo. CEMPRE, 2010. 